\title{
Humanoid Social Robots in the Rehabilitation of Children with Cerebral Palsy
}

\author{
Volodymyr Kozyavkin \\ International Clinic of Rehabilitation \\ 37, Pomiretska str, \\ Truskavets, 82200, Ukraine \\ $+3803224765200$ \\ center@reha.Iviv.ua
}

\author{
Oleh Kachmar \\ International Clinic of Rehabilitation \\ 37, Pomiretska str \\ Truskavets, 82200 , Ukraine \\ +380673537927 \\ okachmar@ic.reha.Iviv.ua
}

\author{
Iryna Ablikova \\ International Clinic of Rehabilitation \\ 37, Pomiretska str \\ Truskavets, 82200 , Ukraine \\ +380632677687 \\ glise@mail.ru
}

\begin{abstract}
To increase the interest of a child in motor training we have tried to use a humanoid social robot that acts like a coach to encourage the patient. The humanoid robot "KineTron" was assembled from commercially available Bioloid Premium robotic kit. Nine movement scenarios of robot behaviour combined with voice and music were developed. During the training session, a therapist activates one of the scenarios by pressing a button on the remote. Evaluation of the Rehabilitation Robot was carried out on a group of six children with Cerebral Palsy, aged between 4-9 years. Rehabilitation Robot was used during 5-7 training sessions. All children and parents liked the sessions with the Rehabilitation Robot. This pilot study suggests that there are potential benefits in using humanoid robots in motor training of patients with cerebral palsy. It appears to be motivating for the child and encourages active participation in rehabilitation activities.
\end{abstract}

\section{Keywords}

Social Robot, Motor Rehabilitation, Cerebral Palsy, Motivation.

\section{INTRODUCTION}

Cerebral palsy is one of the most common causes of motor disability in childhood. The main treatment approach is physical therapy. However, traditional physical therapy that requires multiple repetitions of movements is not motivating for children, and reduces adherence to treatment. One of the ways to encourage active participation in training is to use special rehabilitation computer games that are rapidly developing forming a new field of virtual rehabilitation.

Another approach that is currently explored is the use of humanoid social robots in health care. Much work was done in developing of social robots and human-robot interactions for autism therapy [1].

Some attempts were done to improve hand rehabilitation by using a rehabilitation robot Ursus, designed to conduct exercises with children. This robot is capable of moving his arms, head and mouth and looks like a big Teddy bear [2].

Permission to make digital or hard copies of all or part of this work for personal or classroom use is granted without fee provided that copies are not made or distributed for profit or commercial advantage and that copies bear this notice and the full citation on the first page. To copy otherwise, to republish, to post on servers or to redistribute to lists, requires prior specific permission and/or a fee.

REHAB 2014, May 20-23, Oldenburg, Germany

Copyright (C) 2014 ICST 978-1-63190-011-2

DOI 10.4108/icst.pervasivehealth.2014.255323
Efforts were done in using the Nao humanoid robotic platform in a role of a physiotherapist for rehabilitation and prevention of scoliosis in children [3].

To interest the child with Cerebral Palsy in motor training we have tried in our work to use a humanoid social robot that would act like a coach to encourage the patient.

The aim of this project was to develop movement scenarios for the Rehabilitation Robot and to evaluate possible benefits.

\section{DESCRIPTION OF REHABILITATION ROBOT}

The humanoid robot "KineTron" was used in the study. It was assembled by IT staff from the International Clinic of Rehabilitation from commercially available Bioloid Premium robotic kit.

The Robot is $40 \mathrm{~cm}$ high and weights $1.7 \mathrm{~kg}$. His movements are performed by 18 servomotors ( 6 in each leg and 3 in each hand) operated by microcontroller.

Servomotors execute precise movements with specified speed and force providing feedback about position and tension. Special software RoboPlus was used to arrange complex movement patterns like walking in different directions, body movements, hand gestures etc.

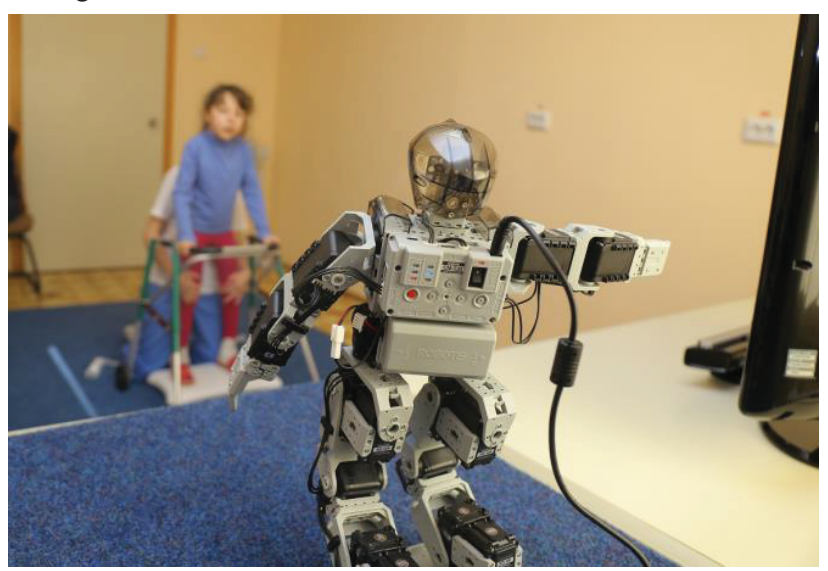

Figure 1. Rehabilitation Robot KineTron during motor training session.

Nine movement scenarios of robot behavior have been developed - three for the beginning of the session, three to encourage patients in the middle of training and three for the final part of the 
session. Each movement scenario is combined with voice and music [4]. During the training session, a therapist activates one of the scenarios by pressing a button on the remote.

Movement scenarios were as follows. Music starts, Robot stands up, goes out to the patient, waives his hand and says: "Hello, I am a Rehabilitation Robot KineTron, and what's your name?" After the child's reply, he says "Nice to meet you" and bows. He suggests training together, points with his hand to the screen, says that he would be watching carefully and squats down.

\section{EVALUATION OF REHABILITATION ROBOT}

Evaluation of the Rehabilitation Robot was carried out on a group of six children with Cerebral Palsy, aged between 4-9 years, undergoing in the International Clinic of Rehabilitation a twoweek course of intensive neurophysiological rehabilitation according to the Kozyavkin Method [5].

This rehabilitation system incorporates different treatment modalities one of which is special computer games, developed by our IT team [6]. For motor training, we are using rehabilitation games with different gaming hardware: Nintendo Wii Fit balance board, MS Kinect, Dance Mat and some other.

Rehabilitation Robot was used during 5 to 7 treatment sessions of Stepping Games with Dance Mat [7] with duration about $20 \mathrm{~min}$. During the sessions, therapists several times executed certain robot behavior scenarios depending on the performance of the child by pressing a button on remote.

After the treatment course patients and parents were asked in an interview about their opinion about the Robot. All children liked the sessions with the Rehabilitation Robot. The children wanted him to be present during their other sessions. The parents made useful suggestions including the following: making him different clothes, expanding the movement scenarios and making separate programs for boys and girls.

Currently the work on improvement of robot performance and movement scenarios is continued.

\section{CONCLUSION}

The pilot study suggests that there are potential benefits in using humanoid robots in motor training of patients with cerebral palsy. It appears to be motivating for the child and encourages active participation in rehabilitation activities.

\section{ACKNOWLEDGMENTS}

Our thanks to the administration of International Clinic of Rehabilitation for financial and administrative support of this work

\section{REFERENCES}

[1] Scassellati B, Admoni H, Matarić M. Robots for Use in Autism Research. Annu Rev Biomed Eng. 2012;14:275-94

[2] Calderita LV, Bustos P, Suárez Mejías C, Ferrer González B and Bandera A. Rehabilitation for Children while Playing with a Robotic Assistant in a Serious Game. Abstracts of VirtRehab 2013, 2013; 09.

[3] Vircikova M. Experience with the Children-Humanoid Interaction in Rehabilitation Therapy for Spinal Disorders. YouTube video http://youtu.be/61ORMeb w94

[4] Kachmar O. Humanoid Robots in Motor Rehabilitation YouTUbe video http://youtu.be/M84NAZ4aJFs

[5] Kozyavkin V.I. 2012. Intensive Neurophysiological Rehabilitation System - the Kozyavkin Method. A Manual for Rehabilitation Specialists. Edited by Kozyavkin V.I. Lviv. Publishing house "Design studio Papuga", 2012 .- 240p.

[6] Kozyavkin V I, Kachmar O O, Markelov V E, Melnychuk V V, Kachmar B O. 2012.Web-based home rehabilitation gaming system for balance training. Proc. 9th Intl Conf. Disability, Virtual Reality \& Associated Technologies, Laval, France, 10-12 Sept. 2012.- p.167-173 http:/www.icdvrat.reading.ac.uk/2012/papers/ICDVRAT201 2 S06N1 Kozyavkin etal.pdf

[7] Kachmar O. Stepping Games for Virtual Rehabilitation. YouTube video http://youtu.be/tDLTu575Ugw 